\title{
Research Square \\ Cropland Displacement Drives Carbon Emission of Grain Transport in China
}

Chengchao Zuo ( $\nabla$ zuochengchao@live.com )

Huazhong Agricultural University https://orcid.org/0000-0002-1419-7989

\section{Cheng Wen}

School of Geography, University of Leeds

\section{Graham Clarke}

School of Geography, University of Leeds

\section{Andy Turner}

School of Geography, University of Leeds

\section{Xinli Ke}

College of Public Administration, Huazhong Agricultural University

\section{Lanping Tang}

College of Public Administration, Huazhong Agricultural University

\section{Article}

Keywords: cropland displacement, carbon emission, grain transport

Posted Date: August 27th, 2021

DOl: https://doi.org/10.21203/rs.3.rs-825010/v1

License: (c) (i) This work is licensed under a Creative Commons Attribution 4.0 International License. Read Full License 
Title Page

Cropland Displacement Drives Carbon Emission of Grain Transport in China 


\section{Main}

Rapid urbanisation around the world has driven a greater need for grain transport. This could largely be attributed to two reasons. Firstly, the fast-growing urban population simply requires more grain to be transported from rural to urban areas. Secondly, to feed the growing cities, food production is being increased in areas further from these main areas of consumption as the growing cities swallow up former agricultural regions at the margins of those cities. Thus, in many countries, croplands have been displaced from land close to city-regions to much more remote, marginal areas due to that process of urbanisation (Meyfroidt et al., 2013; van Vliet, 2019). The increase in distance associated with the shifting production areas for food products is a trend expected to continue alongside urbanization throughout the world (Garnett, 2011), leading to rising energy consumption and carbon emissions of grain transport.

Carbon emissions involved in food production and transportation present a serious challenge to achieving carbon reduction targets set out in the Kyoto and Paris Agreements (Clark et al., 2020), which contributes one-third of the total greenhouse gases emissions of human society (Clark et al., 2020, Crippa et al., 2021, Tukker, 2006). Transport-related emission accounts for 11\%-16\% of carbon emissions of food supply chains (Weber and Matthews, 2008; Garnett, 2011; Wakeland et al., 2012; Crippa et al., 2021). Despite the merit of embedding transport-related carbon emission with the LCA of the food supply chain, previous studies usually oversimplified the transport process by applying emission factors to food-miles data from existing databases, without investigating the details of spatial flows of food between different areas via different transport networks (e.g. road, railway). As a result, these studies have rather limited capacity to adequately measure the impact of land-use changes on transport-related carbon emissions and provide evidence-based policy suggestions on mitigating the emission impact of agricultural and land-use policies.

This research focuses on cropland displacement and the rising carbon emission of grain transport in China during 1990 - 2015. China experienced rapid urbanisation in the last four decades. Its urban population nearly tripled from 310.02 million in 1979 to 875.08 million in 2019 (National Bureau of Statistics of China, NBSC, 2020). Massive cropland $\left(3.31 \times 10^{4} \mathrm{~km}^{2}\right)$ was occupied by urban expansion (Xu et al., 2016). Since 2000, China has implemented a series of cropland protection policies to ensure that the loss of cropland by urban development can be replenished with newly cultivated cropland in areas with lower population density. Such policies have generally stabilized the amount of cropland in China; however, they have increased cropland displacement from the core areas of consumption (Yang et al., 2020). Given the speed and intensity of urbanization and cropland displacement in China, carbon emissions associated with grain transport are believed to be growing fast. Although the issues of cropland displacement and transport-related carbon emissions in China have been studied separately (Feng et al., 2013; Yang et al., 2020; Wang et al., 2011; Chen et al., 2020), few studies have focused on the carbon emission associated with grain transport and the emission impact of cropland displacement. Thus the rest of the paper explores the nature and magnitude of the increase in carbon emission associated with grain transport in China.

This paper develops a model-based system first introduced by Zuo et al. $(2013,2018)$ to estimate the carbon emissions associated with the changing transportation of grain in China between 1990 and 2015. First, we developed a spatial interaction model to estimate the spatial flows of grain (which we define as rice, wheat, maize, and soybean) from the changing areas of production to the areas of consumption. These flows are disaggregated by transport modal choice. Second, based on these flow patterns, the total carbon emission produced by the transport system for grain is then estimated, measured by $\mathrm{CO}_{2}$ emission equivalent $\left(\mathrm{kgCO}_{2} \mathrm{e}\right)$, again based on transport mode and route. The changing carbon emission associated with grain transport is then revealed by comparing the two urbanisation stages (1990 and 2015). Once built, the model allows us to examine a series of what-if scenarios designed to look at the emission impact of cropland displacement, population growth, dietary change, and transport infrastructure development. 


\section{Results}

\section{Extended Distances between Population and Cropland}

Between 1990 and 2015, the population of China grew from 1.13 billion to 1.37 billion. Figs 1a and $1 \mathrm{~b}$ show significant population growth in the southeast coastal areas and significant population decreases in the Northeast and central regions. Significant cropland expansion occurred in Northeast and Northwest China during the same period, whereas significant cropland shrinkages occurred in Central and Eastern China (Fig. 1c \& 1d). Figs 1e and 1f show that at the prefectural level, the average distance between the mean centres (Methods Equation [2]) of population and cropland increased from $10.89 \mathrm{~km}$ to $12.59 \mathrm{~km}$ between 1990-2015; and 251 out of 347 (approx. $72 \%$ ) prefectures in China experienced a greater separation between population and cropland (grain production) centres. At the national level, the mean centre of cropland moved $62.53 \mathrm{~km}$ north, while the mean centre of population moved $17.91 \mathrm{~km}$ south. As a result, the distance between the national mean centre of cropland and population extended from $259.25 \mathrm{~km}$ to $338.36 \mathrm{~km}$ between 1990 and 2015 .

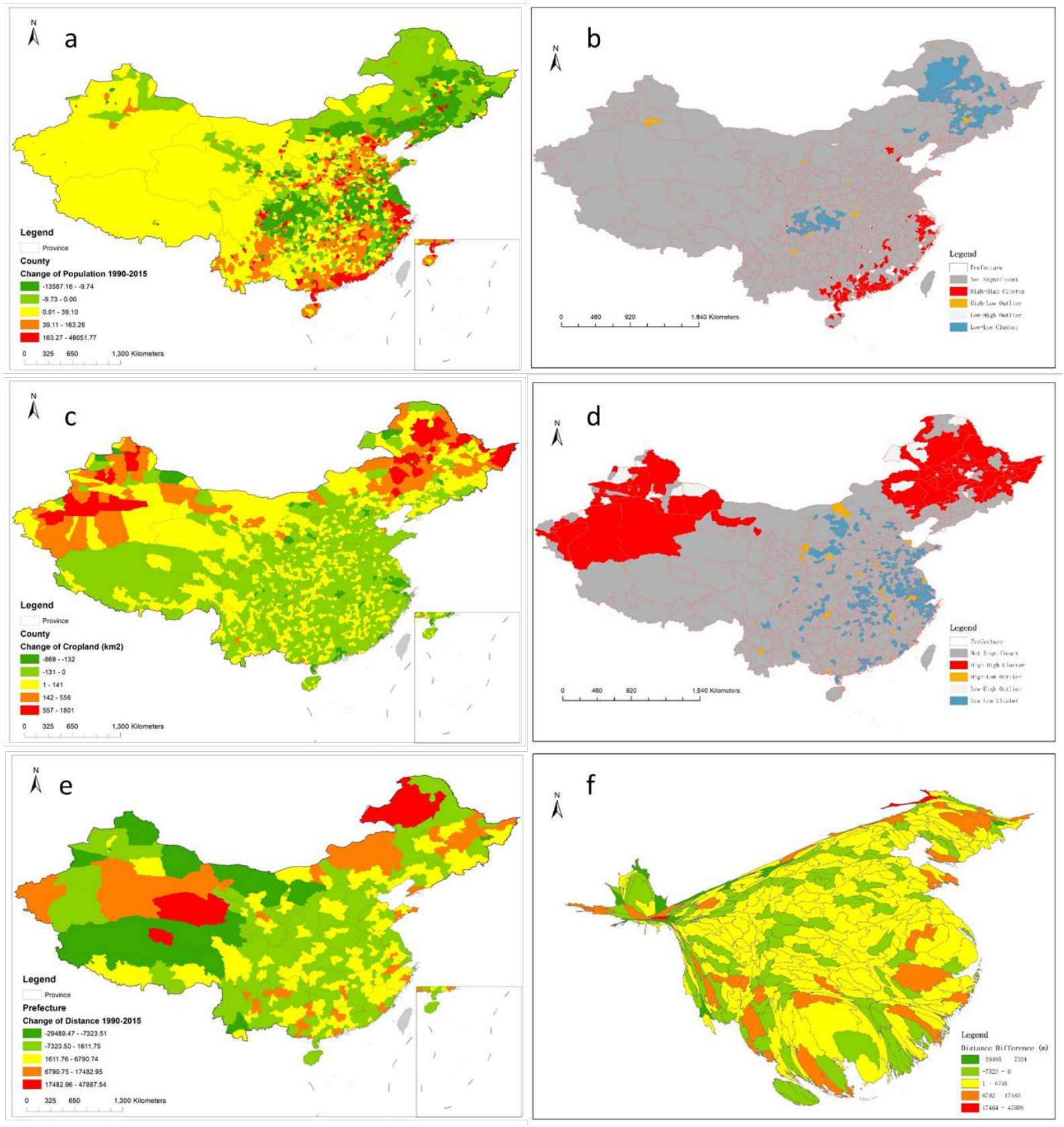


Fig. 1 Change of Population and Cropland Distribution in China 1990-2015: a) Change of population by county, b) The local indicators for spatial association (LISA; Anselin, 1995) map of population growth, c) Change of cropland area by county, d) LISA map of the change of cropland area, e) Change of distance between the mean centre of population and cropland at prefectural level; f) Cartogram of change of distance between the mean centre of population and cropland (rescaled by the population of each prefecture)

\section{Grain Consumption and Production}

We estimated the grain consumption of each prefecture in 1990 and 2015 based on three types of grain consumption: staples, animal-feed, and industrial \& other uses (e.g. grain-based snacks and alcoholic drinks; Methods Equation [1]). Results indicate a transformed grain consumption pattern during this period due to the changing dietary structure of Chinese people. First, grain consumption as staples dropped nearly 30\% from 266.52 million-ton in 1990 to 187.20 million-ton in 2015 despite the population growth. Second, grain consumption for feeding animals more than tripled from 71.27 million-ton to 237.72 million-ton, which outranked staples as the largest type of grain consumption in 2015. Lastly, industrial \& other uses of grain also increased from 130.21 million-ton to 223.13 millionton.

Overall, grain production in China grew from 468.01 million-ton to 648.06 million-ton between 1990 and 2015. Spatial distributions of grain production at the prefecture level show that, as a result of cropland displacement towards "marginal land" (Kuang et al., 2021), the increase in grain production occurred primarily in the north, Northeast and Northwest of China (Fig. 2 a \& b). In comparison, an increase in grain consumption mainly occurred in the east and southeast of China (Fig. 2 c \& d). Compared to 1990, the whole country was more reliant on grain supplies originated in northern China by 2015 (Fig. 2 e \& f). The distance between national mean centres of grain production and consumption extended from $178.54 \mathrm{~km}$ to $328.93 \mathrm{~km}$. 

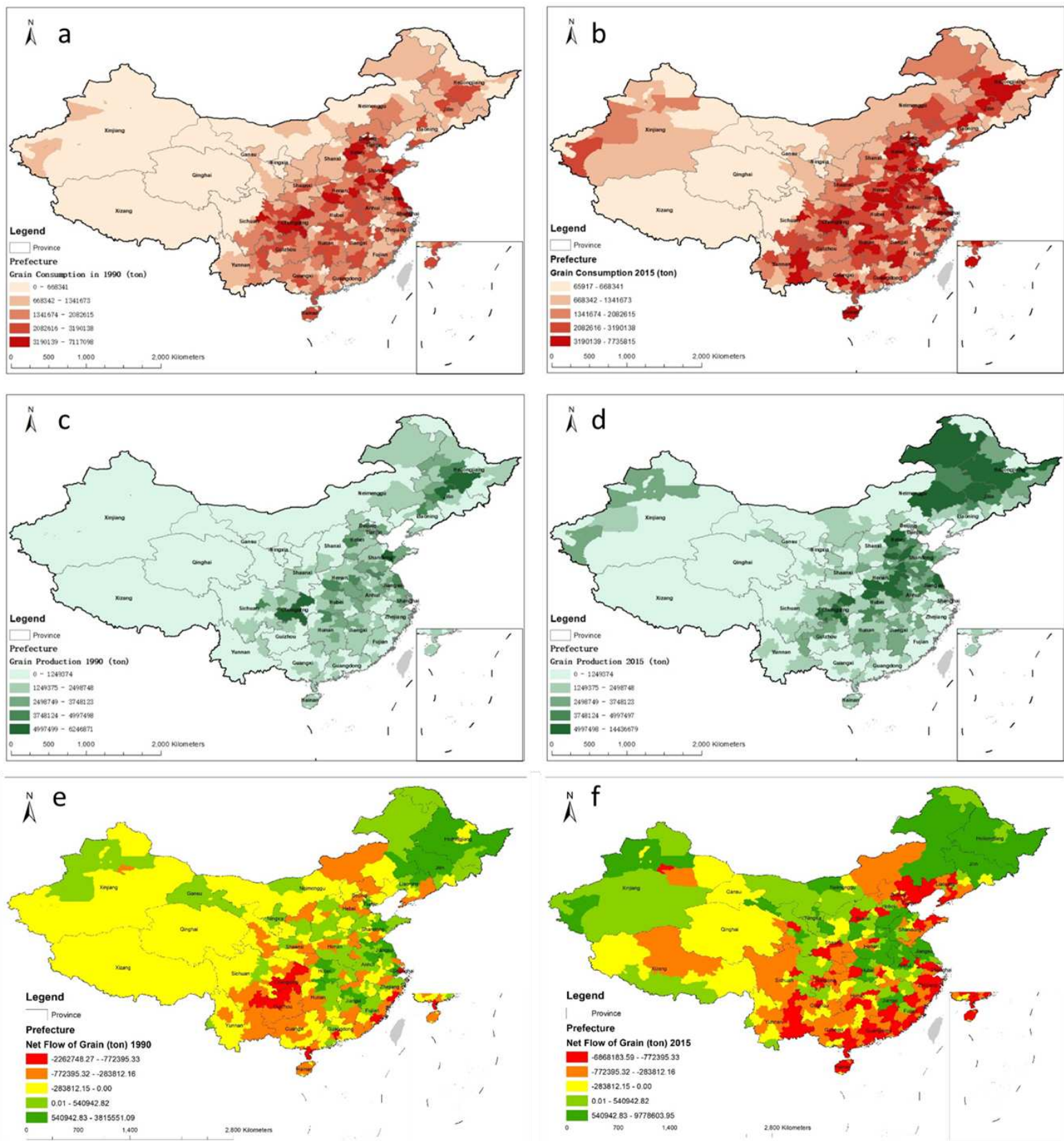

Fig. 2 Spatial Distribution of Grain Consumption and Production in China at the Prefecture Level: grain consumption by prefecture in a) 1990 and b) 2015; grain production by prefecture in c) 1990 and d) in 2015; net-flow (production-consumption) of grain in e) 1990 and f) 2015, green tones indicate net-exporters, while yellow to red tones indicate net-importers.

\section{Spatial Flows of Grain Transport}

Harnessing the doubly constrained spatial interaction model (Methods Equation [3]-[8]) using three types of transport network data (road, railway, and waterway), we estimated the spatial flow of grain transport between each pair of prefectures of China in both 1990 and 2015. Aggregated results at the provincial level show that the scale of inter-provincial grain flows grew from 64.33 million-ton to 168.03 million-ton, and the general pattern of grain transport turned more north-to-south than east-towest (Fig.3). In 1990, the northeastern provinces were the major grain suppliers for the North and Northwest of China, while the eastern provinces of China were the major suppliers for central and 
southern China. In 2015, Neimenggu (Inner-Mongolia) outranked Liaoning as the third largest grain supplier in northern China after Heilongjiang and Jilin. Hunan and Hubei Provinces' role as major grain suppliers in central China declined, while Henan became the biggest supplier in the Central-South region. Provinces in the East of China (i.e. Zhejiang and Fujian) turned from net grain exporters to net importers. In Guangdong and Guangxi, two of the most southerly provinces in the Chinese mainland, the market share of northern-origin grain increased from less than $20 \%$ to approximately $50 \%$. These changes echo the fact that grain production in China has been moving northward and the transport distances have been extending during this 25 year period.
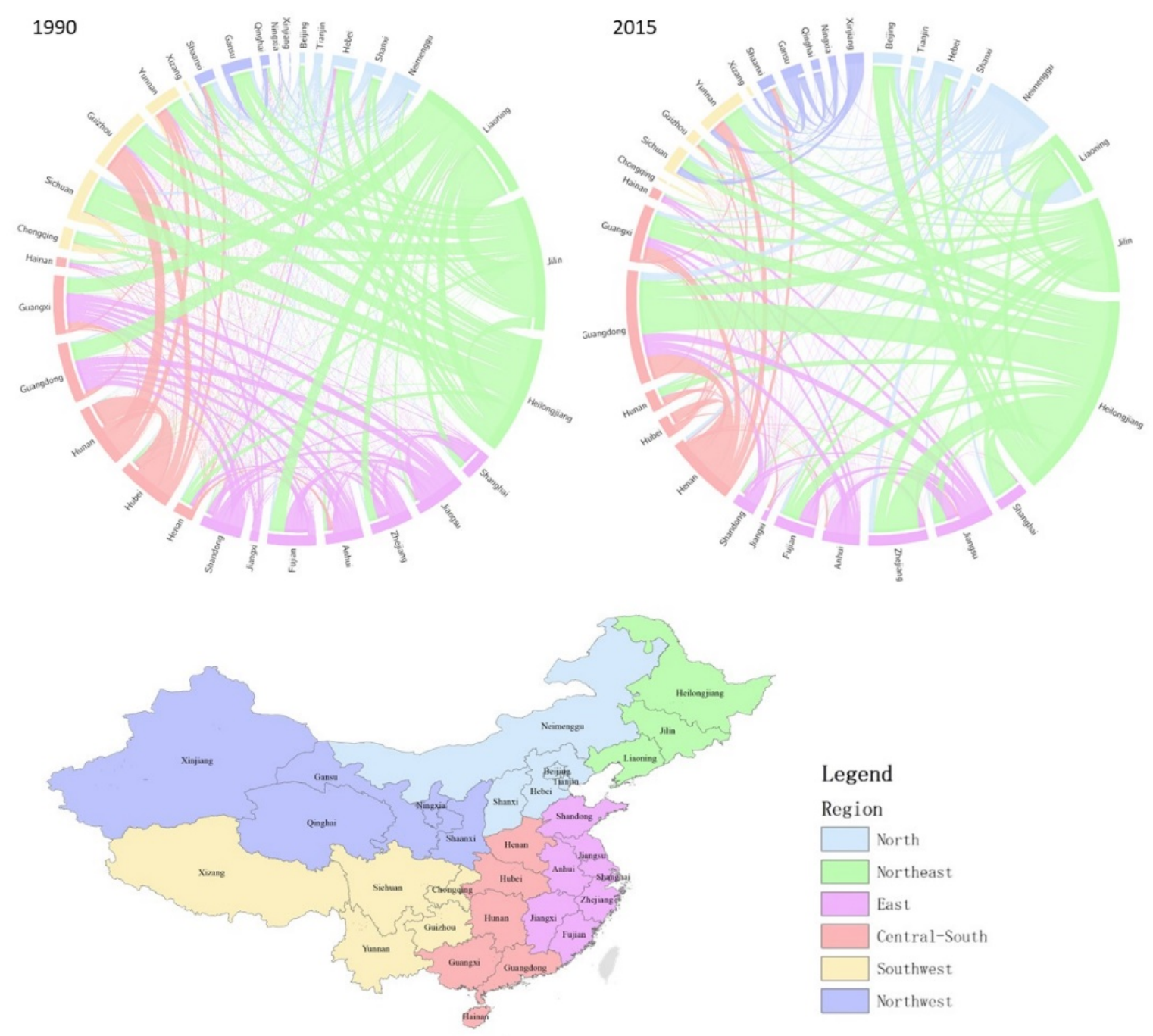

Fig.3 Inter-provincial Flow of Grain Transport in China (1990 and 2015): the arcs on the outer ring and the ribbons between the arcs. Each arc on the outer ring indicates a province, coloured by the region. The length of the arc represents the grain flux (inflow + outflow) of the province. The ribbons between the two arcs represent the grain flows between the export provinces and the import provinces, and the colour of each ribbon matches the colour export province. The width of the ribbon indicates the volume of the flow of grain.

A breakdown of the inter-provincial flow of grain by the three transport modes (Fig 4) shows that the railway has been the most critical transport mode for supplying grain to Southwest China and that grain from the Northeast dominated the market share of grain transported by railway. Due to the railway 
network development in Northwest China since the early 2000s, grain exported from Xinjiang Province has been one of the most significant changes in grain transport by railway between 1990 and 2015. The waterway mode of travel was mostly responsible for transporting grain from Northeast and East China to Central-South China; Guangdong Province was the largest destination for the waterway-transported grain (accounting for 30\% in 1990 and 45\% in 2015). Road transport was mainly for short-distance transport within all regions. Inter-regional grain transport by road was rare in 1990; however, it became more common in 2015 due to the increasing distances between grain production and consumption.

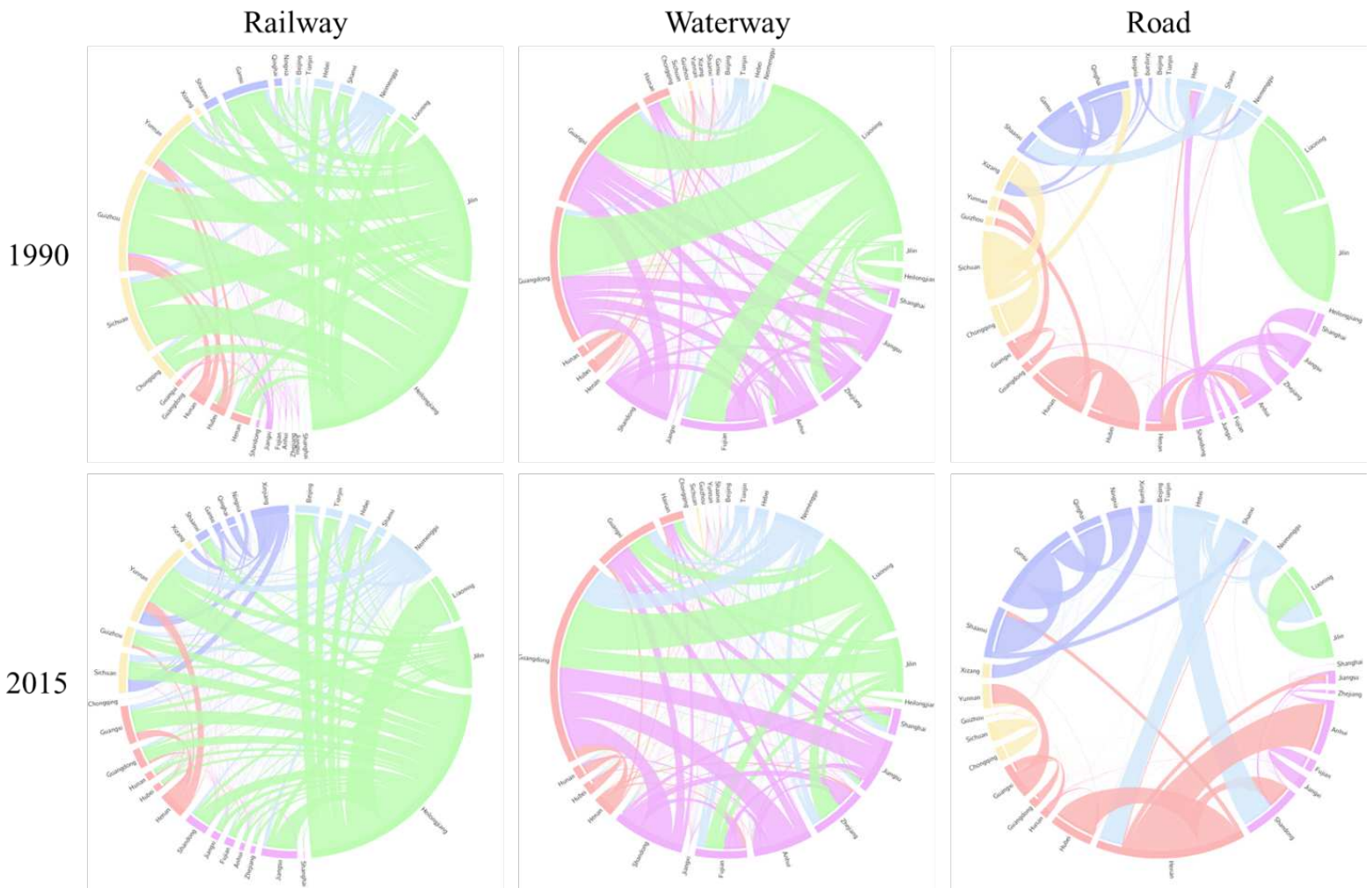

Fig. 4 Inter-provincial flow of grain by transport mode in 1990 and 2015

\section{Carbon Emission Associated with Grain Transport}

Based on the modelled spatial flows of grain transport and the carbon emission conversion factors of the different transport modes, we estimate that carbon emissions associated with grain transportation in China more than doubled from 4.46 million-ton in 1990 to 10.73 million-ton in 2015. In terms of different transport modes, the largest contributor has been grain transport by railway, which increased 2.5 times from 1.774 million-ton to 4.502 million-ton. The carbon emissions associated with grain transport by road nearly doubled from 2.156 million-ton to 4.181 million-ton. Grain transport by waterway contributed the least proportion of carbon emissions, which, however, almost tripled from 0.704 million-ton to 2.047 million-ton. We also estimated the carbon intensity $\left(\mathrm{kg} \mathrm{CO}_{2}\right.$ emission equivalent per ton of grain) of grain transportation related to the three types of grain consumption (staples, animal-feeding, industrial \& other uses). Grain for industrial \& other uses had the highest transport-related carbon intensity, which grew from $9.64 \mathrm{kgCO}_{2} \mathrm{e} /$ ton to $18.11 \mathrm{kgCO}_{2} \mathrm{e} /$ ton between 1990 and 2015. The transport-related carbon intensity of grain for staples and animal-feed also grew from $9.52 \mathrm{kgCO}_{2} \mathrm{e} /$ ton and $9.31 \mathrm{kgCO}_{2} \mathrm{e} /$ ton to $17.63 \mathrm{kgCO}_{2} \mathrm{e} /$ ton and $14.26 \mathrm{kgCO}_{2} \mathrm{e} /$ ton respectively.

We further disaggregated the grain transport-related carbon intensity to the prefecture-level on both the production and consumption sides (Methods equation [15] and [16]). The model results suggest that 
grain consumed in prefectures in the south and east coastal areas had higher transport-related carbon intensities than in other parts of China, except Xizang (Tibet) and Qinghai Provinces in the QinghaiTibet Plateau which has a harsh environment for grain production and relatively poor transport infrastructure (Fig. 5a). For instance, the average transport-related carbon intensity of grain consumed within the south-coastal Guandong Province was almost six times higher than that in Hubei Province in Central China. On the production side, the transport-related carbon intensity of grain produced in prefectures in northern China is estimated to be generally higher than in southern China (Fig. 5b). For instance, the average transport-related carbon footprint of grain produced in the northeastern Province of Heilongjiang $\left(42.87 \mathrm{kgCO}_{2} \mathrm{e} / \mathrm{ton}\right)$ was 20 times more than that in the southern province of Guangdong $\left(2.05 \mathrm{kgCO}_{2} \mathrm{e} / \mathrm{ton}\right)$. Extended Data Table 1 shows the average transport-related carbon intensity of grain production and consumption in each province.
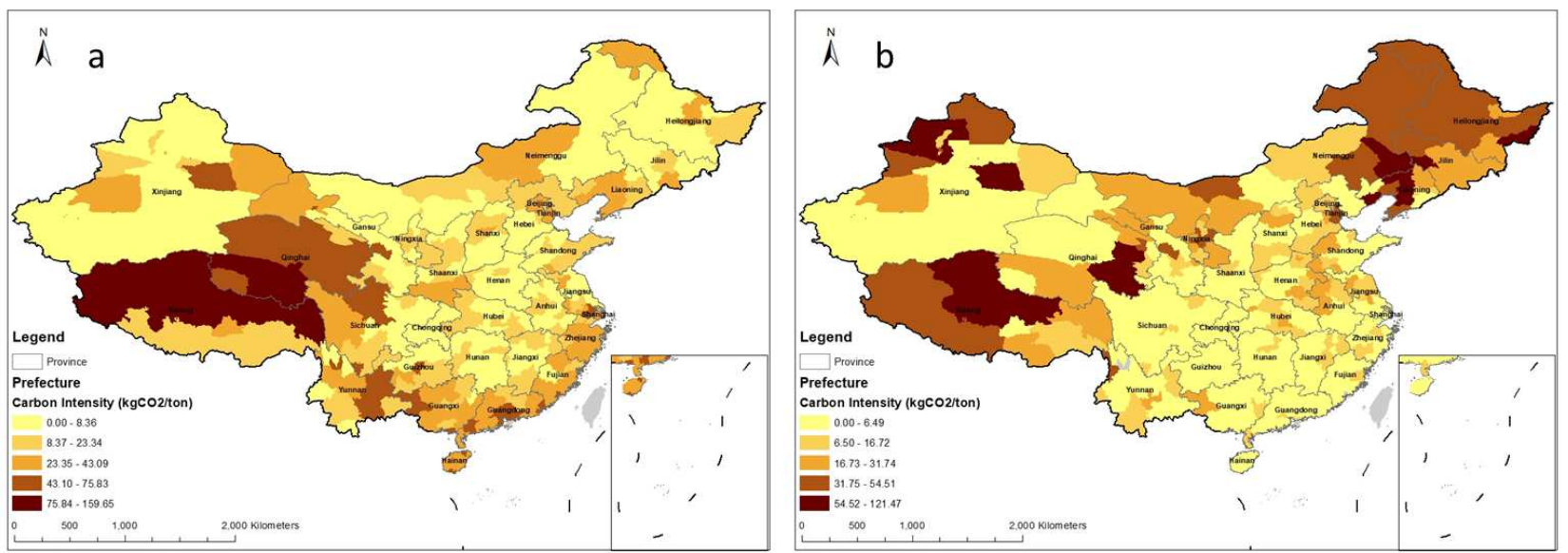

Fig.5 Transport-related Carbon Intensity (kgCO 2 e/ton) at the Prefecture Level (2015): a) grain consumption; b) grain production

\section{Drivers of Grain Transport Carbon Emission}

We applied a scenario analysis to identify the impacts of multiple factors on grain transport carbon emissions (see Fig 6a). We found that cropland displacement contributed 3.79 million-ton, accounting for $60.4 \%$ of the incremental carbon emissions in China between 1990 and 2015 . The change of dietary structure and population growth contributed 1.99 million-ton (31.7\%) and 1.04 million-ton (16.6\%), respectively. However, the development of transport infrastructures, such as newly built highways and railways in western China, helped reduce 0.54 million-ton of carbon emissions associated with grain transport, equivalent to half of the increment related to population growth (see Fig 6b).

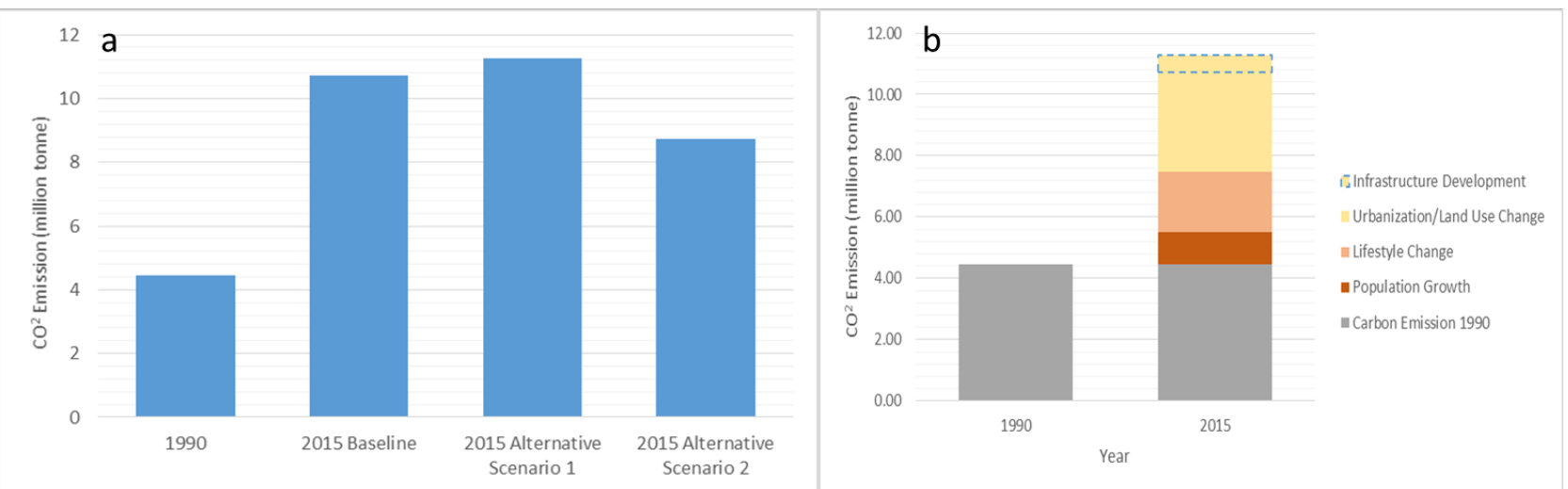

Fig.6 a) Transport related carbon emission under different scenarios, and b) Drivers of increased carbon emission of grain transport 


\section{Discussion}

China is facing dual challenges of reducing carbon emissions and feeding the largest population in the world. On the one hand, the country has announced its ambitious national strategy to achieve peak carbon emissions by 2030 and to be carbon neutral by 2060 (Mallapaty, 2020). A series of carbon emission targets have been set up in its 14th five-year plan (2021-2025) (Hou, 2020). The agriculture department plays a key role in achieving carbon emission targets. However, the extended distance of grain transport and the associated rising carbon emissions have not received sufficient attention. In this research, we found that $72 \%$ of prefectures in China experienced a greater separation between its population centres and the cropland centres that feed them. This distance between the national mean centres of grain production and consumption extended by $150.39 \mathrm{~km}$ during $1990-2015$. We estimate that the carbon emissions of grain transport consequently more than doubled during this same period.

On the other hand, securing the food supply to its growing population has been a long-standing challenge for China. To maintain self-sufficiency (as high as $95 \%$ in grain supply) China has endeavoured to keep its total amount of cropland despite the great pressure of rapid and massive urbanisation. One of the consequences has been cropland displacement (van Vliet et al., 2017; Ke et al., 2017), which, as we estimate, contributed more than $60 \%$ of the increase in carbon emissions of grain transport between 1990 and 2015. In 2018, a revised cropland protection policy was introduced in China to allow cross-provincial cropland displacement (before that, displacement must be fulfilled within the same province). This new policy is expected to intensify cropland displacement across the country (Yang et al., 2020; Ke et al., 2020) and further increase carbon emissions from transporting grain from production to consumption areas. Here we argue for more synergic considerations of the emission impact of increasing the food-miles in agricultural policies. Based on this research, we provide the following policy suggestions on reducing the carbon emissions of grain transport in China.

First, we found that the east and south coast of China with the highest population density have almost the highest transport-related carbon intensity for grain consumption, whereas areas with the highest grain output have the highest transport-related carbon intensity for grain production (supply). In comparison, central China (e.g. Hubei Province) has relatively low transport-related carbon intensity on both supply and consumption side; however, both the proportions of grain output and population of central China to the whole country were declining during 1990 - 2015. We therefore suggest that encouraging and facilitating the development of central China as a major grain production and economic centre with a higher population density could help reduce the total gain transport distance and associated carbon emissions.

Second, our model results show that the change in dietary structure contributed $31.7 \%$ of the increase in grain transport carbon emissions in China between 1990 and 2015. Although the environmental impacts of dietary change in China is not a new topic (He et al., 2018; Xiong et al., 2020), we provide new insights from the different perspectives of its impact on grain consumption and transport. Our results show that the fast-growing grain consumption for feeding animals and industrial \& other uses has been accompanied with rising transport-related carbon intensity, indicating that more meat and grain-based snacks are consumed in modern China. Given that meat, snacks, and alcoholic drinks are usually with much higher added value than staple grains, we suggest that building a more localised supply chain for those high added value commodities at the downstream value chain of grain production could both benefit local economies and help reduce carbon emissions related to grain transport. This echoes the 'local food' movement in some western countries (Smith et al., 2005; Engelhaupt, 2008).

Lastly, we found that the improvement of transport infrastructure, especially the development of the railway network in western China, had offset part of the increased grain transport carbon emissions driven by cropland displacement, change of dietary structure, and population growth. Since the carbon emission per ton-km of railway and waterway transport is much lower than that of road transport, we suggest that further increasing railway \& waterway transport capacity is important for reducing the pressure of rising emissions from grain transport. Moreover, as the carbon-intensive road transport contributed nearly $40 \%$ of the grain transport emissions in 2015 , and its market share of long-distance 
grain transportation has been increasing between 1990 and 2015, we also argue that technological evolution in clean energy and electric high gross vehicles must play an important role in reducing the grain transport related emissions in the future.

Cropland displacement is not a unique phenomenon in China but a common issue in many countries across the world (Meyfroidt et al. 2013; van Vliet 2019). The negative environmental impacts of cropland displacement need to be taken better account of in land use and agriculture policy-making practices. This paper demonstrates a systematic evaluation framework to estimate the carbon emissions of grain transport and identifies the emission impact of cropland displacement as well as other factors. Although a few simplified assumptions were adopted in the modelling process, and the actual grain transport emission in a specific year between 1990 and 2015 was not estimated (largely due to data availability), our estimation results of the increased food miles (ton- $\mathrm{km}$ ) and related carbon emissions between the two years were validated through robust model calibration (reported in Supplementary Information). In a wider context, our research findings contribute to a better understanding of the life cycle environmental impact within the food supply chain. The methodology proposed in this study could be applicable to a wide range of other commodities that involve trans-regional production and consumption, both in China and other countries.

\section{References}

Anselin, L. (1995). Local indicators of spatial association-LISA. Geographical analysis, 27(2), 93115 .

Aubert, C. (2008). Food security and consumption patterns in China: the grain problem. China Perspectives, 2008(2008/2), 5-23.

Carlson, K., Gerber, J., Mueller, N. et al. Greenhouse gas emissions intensity of global croplands. Nature Climate Change 7, 63-68 (2017). https://doi.org/10.1038/nclimate3158

Chen, X., Shuai, C., Wu, Y., \& Zhang, Y. (2020). Analysis on the carbon emission peaks of China's industrial, building, transport, and agricultural sectors. Science of the Total Environment, 709, 1-8.

Chen, Y., Yang, Y., Zhou. L. (2014) Discussion on Selection of Grain Logistic Modes in China, Railway Freight Transport 2014(11), 12-17 in Chinese

Cheng, W., Gao, X., Ma, T., Xu, X., Chen, Y., \& Zhou, C. (2018). Spatial-temporal distribution of cropland in China based on geomorphologic regionalisation during 1990-2015. Acta Geographica Sinica, 73(9), 1613-1629.

Clark, M. A., Domingo, N. G., Colgan, K., Thakrar, S. K., Tilman, D., Lynch, J., ... \& Hill, J. D. (2020). Global food system emissions could preclude achieving the $1.5^{\circ}$ and $2^{\circ} \mathrm{C}$ climate change targets. Science, 370(6517), 705-708.

Cole, C. V. et al. Global estimates of potential mitigation of greenhouse gas emissions by agriculture. Nutr. Cycl. Agroecosyst. 49, 221-228 (1997).

Crippa, M., Solazzo, E., Guizzardi, D., Monforti-Ferrario, F., Tubiello, F. N., \& Leip, A. (2021). Food systems are responsible for a third of global anthropogenic GHG emissions. Nature Food, 1-12.

Cui, L. and Shi, J., 2012. Urbanisation and its environmental effects in Shanghai, China. Urban Climate, 2, pp.1-15.

Dalin, C., Qiu, H., Hanasaki, N., Mauzerall, D. L., \& Rodriguez-Iturbe, I. (2015). Balancing water resource conservation and food security in China. Proceedings of the National Academy of Sciences, 112(15), 4588-4593. 
Dawson, R.J., Hall, J.W., Barr, S.L., Batty, M., Bristow, A.L., Carney, S., Dagoumas, A., Evans, S., Ford, A., Harwatt, H., Köhler, J., Tight, M.R., Walsh, C.L., Zanni, A.M., 2009. A blueprint for the integrated assessment of climate change in cities. Tyndall Working Paper 129, pp. 26.

Engelhaupt, E (2008). "Do food miles matter? yes". Environmental Science \& Technology. 42 (10): 3482. doi:10.1021/es087190e

Foster, C, Holmes, M, Wiltshire, J et al. (2012) The environmental effects of seasonal food purchase: a case study. 8th Int. Conf. LCA in the Agri-Food Sector, 620.

https://:/colloque4.inra.fr/var/lcafood2012/storage/fckeditor/file/Proceedings/Proceedings\%20\%20LCA\%20Food\%202012\%20-\%20ISBN.pdf

Garnett, T., 2011. Where are the best opportunities for reducing greenhouse gas emissions in the food system (including the food chain)?. Food policy, 36, pp.S23-S32.

He, P., Baiocchi, G., Hubacek, K. et al. The environmental impacts of rapidly changing diets and their nutritional quality in China. Nat Sustain 1, 122-127 (2018). https://doi.org/10.1038/s41893018-0035-y

Hou, L. (2020). Nation to set obligatory carbon goals, China Daily, Oct. 29th 2020, http://english.www.gov.cn/statecouncil/ministries/202010/29/content_WS5f9a019dc6d0f7257693e9 47.html

Hong, C., Burney, J. A., Pongratz, J., Nabel, J. E., Mueller, N. D., Jackson, R. B., \& Davis, S. J. (2021). Global and regional drivers of land-use emissions in 1961-2017. Nature, 589(7843), 554561.

Houghton, R.A., House, J.I., Pongratz, J., Van Der Werf, GRR, DeFries, R.S., Hansen, M.C., Le Quéré, C. and Ramankutty, N. (2012). Carbon emissions from land use and land-cover change. Biogeosciences, (12), pp.5125-5142.

Jiang, S., Wang, J., Zhao, Y., Shang, Y., Gao, X., Li, H., Wang, Q. and Zhu, Y., 2017. Sustainability of water resources for agriculture considering grain production, trade and consumption in China from 2004 to 2013. Journal of Cleaner Production, 149, pp.1210-1218.

Ke X, van Vliet J, Zhou T, Verburg PH, Zheng W, Liu X (2017) Direct and indirect loss of natural habitat due to built-up area expansion: a model-based analysis for the city of Wuhan, China. Land Use Policy 74:231-239. https://doi.org/10.1016/j.landusepol.2017.12.048

Ke, X., Zhou, Q., Zuo, C., Tang, L., \& Turner, A. (2020). Spatial impact of cropland supplement policy on regional ecosystem services under urban expansion circumstance: a case study of Hubei Province, China. Journal of Land Use Science, 1-17.

Kuang, W., Liu, J., Tian, H., Shi, H., Dong, J., Song, C., Li, X., Du, G., Hou, Y., Lu, D. and Chi, W., 2021. Cropland redistribution to marginal lands undermines environmental sustainability. National Science Review. https://doi.org/10.1093/nsr/nwab091

Lai, L., Huang, X., Yang, H., Chuai, X., Zhang, M., Zhong, T., Chen, Z., Chen, Y., Wang, X. and Thompson, J.R., (2016). Carbon emissions from land-use change and management in China between 1990 and 2010. Science Advances, 2(11), p.e1601063.

Linquist, B., Groenigen, K. J., Adviento-Borbe, M. A., Pittelkow, C. \& Kessel, C. (2012) An agronomic assessment of greenhouse gas emissions from major cereal crops. Glob. Chang. Biol. 18, 194-209.

Liu J, Kuang W, Zhang Z, Xu X, Qin Y, Ning J, ZhouW, Zhang S, Li R, Yan C, Wu S, Shi X, Jiang N, Yu D, Pan X, Chi W (2014a) Spatiotemporal characteristics, patterns and causes of land use changes in China since the late 1980s. J. Geogr. Sci. 24: 195-210. https://doi.org/10.1007/s11442014-1082-6

Liu L, Xu X, Liu J, Chen X, Ning J (2014b) Impact of farmland changes on production potential in China during 1990-2010. J Geogr Sci 25(1):19-34. https://doi.org/10.1007/s11442-015-1150-6 
Mallapaty, S. (2020). How China could be carbon neutral by mid-century. Nature, 586(7830), 482483.

Meyfroidt P, Lambin EF, Erb KH, Hertel TW (2013) Globalisation of land use: distant drivers of land change and geographic displacement of land use. Curr Opin Environ Sustain 5:438-444. https://doi.org/ 10.1016/j.cosust.2013.04.003

Nelson, R.G., Hellwinckel, C.M., Brandt, C.C., West, T.O., De La Torre Ugarte, D.G. and Marland, G., 2009. Energy use and carbon dioxide emissions from cropland production in the United States, 1990-2004. Journal of environmental quality, 38(2), pp.418-425.

Saunders, C \& Barber, A (2008) Carbon footprints, life cycle analysis, food miles: global trade trends and market issues. Polit Sci 60, 73-88.

Smith, A, Watkiss, P, Tweddle, G et al. (2005) The Validity of Food Miles as an Indicator of Sustainable Development: Final report. DEFRA report ED50254.

http://archive.defra.gov.uk/evidence/economics/foodfarm/reports/documents/foodmile.pdf

Sonnino, R., 2016. The new geography of food security: exploring the potential of urban food strategies. The Geographical Journal, 182(2), pp.190-200.

van Vliet J, Eitelberg DA, Verburg PH (2017) A global analysis of land take in cropland areas and production displacement from urbanisation. Glob Environ Chang 43:107-115.

https://doi.org/10.1016/j.gloenvcha.2017.02.001

Wang, W., Zhang, M., Zhou, M., 2011.Using LMDI method to analyse transport sector CO2 emissions in China. Energy 36, 5909-5915.

Wang, L., Li, C., Ying, Q., Cheng, X., Wang, X., Li, X. \& Gong, P. (2012). China's urban expansion from 1990 to 2010 determined with satellite remote sensing. Chinese Science Bulletin, 57(22), 28022812.

Webb, J, Williams, AG, Hope, E et al. (2013) Do foods imported into the UK have a greater environmental impact than the same foods produced within the UK? Int J Life Cycle Assess 18, $1325-1343$

Weber, C.; Matthews, H. (2008). "Food-Miles and the Relative Climate Impacts of Food Choices in the United States". Environmental Science \& Technology. 42 (10): 3508-3513.

doi:10.1021/es702969f.

Xu, X. and Lan, Y., 2017. Spatial and temporal patterns of carbon footprints of grain crops in China. Journal of Cleaner Production, 146, pp.218-227.

Xiong, X., Zhang, L., Hao, Y., Zhang, P., Chang, Y. and Liu, G., 2020. Urban dietary changes and linked carbon footprint in China: a case study of Beijing. Journal of environmental management, 255, p.109877.

Yang, B., Ke, X., van Vliet, J. et al. Impact of cropland displacement on the potential crop production in China: a multi-scale analysis. Reg Environ Change 20, 97 (2020).

https://doi.org/10.1007/s10113-020-01690-x

Yang, B., Ke, X., van Vliet, J., Yu, Q., Zhou, T., \& Verburg, P. H. (2020). Impact of cropland displacement on the potential crop production in China: a multi-scale analysis. Regional Environmental Change, 20(3), 1-13.

Yin, Fang, Sun, Zhanli, You, Liangzhi \& Müller, Daniel (2018) Increasing concentration of major crops in China from 1980 to 2011, Journal of Land Use Science, 13:5, 480-493, DOI:

$10.1080 / 1747423 X .2019 .156783$

Yue WZ, Fan PL, Wei YHD, Qi JG (2014) Economic development, urban expansion, and sustainable development in Shanghai. Stoch Env Res Risk Assess. doi:10.1007/s00477-012-0623-8 
Zuo, C., Birkin, M., Clarke, G., McEvoy, F., \& Bloodworth, A. (2013). Modelling the transport of primary aggregates in England and Wales: Exploring initiatives to reduce $\mathrm{CO} 2$ emissions. Land use policy, 34, 112-124.

Zuo, C., Birkin, M., Clarke, G., McEvoy, F., \& Bloodworth, A. (2018). Reducing carbon emissions related to the transport of aggregates: Is road or rail the solution?. Transport Research Part A: Policy and Practice, 117, 26-38. 


\section{Methods}

\section{Modelling Framework}

Modelling grain transport, in terms of flow and transport mode, based on the distribution of supplies and demands (land-use) is essential for understanding the impacts of urbanisation and cropland displacement on grain transport. Since the 1950s, many efforts have been made to model commodity or population flows between places, including multi-regional input-output models (Leonitif, 1963), linear programming (Reed et al., 2000; Dalin et al., 2014), spatial price equilibrium models (Samuelson, 1952; Ricci, 1999), and spatial interaction models (Wilson, 1974; Clarke and Birkin, 2018). In transport geography, spatial interaction models (SIMs) are the most commonly used approach to modelling the flows of freight or people between locations based on the distribution of supply and demand. Zuo et al. $(2013,2018)$ demonstrated a modelling framework, which adopted a doubly-constrained SIM to simulate the inter-regional flows of aggregates in the UK. With this modelling framework, they were able to evaluate the impacts of aggregate supply policies on carbon emissions.

Extend Data Fig.2 illustrates the modelling framework we applied to estimate the carbon emissions associated with grain transport in China. We first established data sets concerning grain production and consumption at the prefecture level in China. Then, we identify the shortest route between each pair of prefectures in China by three different transport modes: road, railway and waterway (including both inland waterway and coastal transport by sea). Since the number and the boundary of prefectures in China vary over time, to ensure consistency and to make the results comparable, we chose the 2010 prefecture boundary data as the basic unit. The road and railway transport network data were extracted from OpenStreetMap for 1990 and 2015. Table 1 summarises the key statistics about the data we used in this research. Next, we estimated the transport costs between each pair of prefectures based on the distance and the corresponding transport mode. As a full interaction matrix of real flows was not available as published data, a doubly constrained spatial interaction model was adopted to generate the spatial flows of grain between prefectures according to the transport cost, grain production levels at the origin prefecture and grain consumption levels at the destination prefecture. So, the ton-km of grain between each pair of prefectures in China was estimated. Then, in turn, we estimated the carbon emissions of grain transport for each prefecture origin-destination possibility based on the ton-km of grain, the corresponding transport modes and carbon emission conversion factors. Finally, we applied what-if scenario analysis to identify the impacts of multiple factors (e.g. cropland displacement, development of transport infrastructure) on carbon emissions of grain transport at the prefecture level. Details of each step are explained in more detail below.

\section{Grain Consumption and Output by Prefecture in 1990 and 2015}

The grain consumption of each prefecture was estimated based on three types of grain: staples, animal-feed, and industrial \& other uses. The staple grain consumption was estimated based on the number of urban and rural residents in each prefecture. The animal-feed grain consumption was estimated by applying statistics on the production of meat to the corresponding grain-to-meat ratios. Due to the lack of relevant official statistics data, the grain for industrial and other uses was estimated by applying a fixed ratio factor to the population. Thus, the consumption of grain for each prefecture was calculated as equation [1].

$$
D_{j}={ }^{I} G R * P o p_{j}+{ }_{U}^{R} G R *{ }_{U} P o p_{j} * U_{j}+{ }_{R}^{R} G R *{ }_{R} P o p_{j}+{ }_{P}^{F} G R *{ }_{P} M t_{j}+{ }_{O}^{F} G R *{ }_{o} M t_{j}[1]
$$

where $P o p_{j},{ }_{U} P o p_{j}$, and ${ }_{R} P o p_{j}$, are the population, urban population, rural population in prefecture j; ${ }_{U}^{R} G R$ and ${ }_{R}^{R} G R$ are the ratio grain consumption per capita for urban residents and rural residents, respectively; ${ }^{I} G R$ represents the grain for industry (and other) uses per capita; ${ }_{P} M t_{j}$ and ${ }_{O} M t_{j}$ represent the meat outputs in prefecture $\mathrm{j} ;{ }_{P} G R$ and ${ }_{O}^{F} G R$ represent the grain-to-meat ratios for pork and 
other meat, respectively. The urban population rate and meat output of each prefecture in 2015 were obtained from the yearbook of each province. The corresponding numbers for 1990 were extracted from the 1990 census and 1990 agricultural survey.

The grain output of each prefecture in 1990 was aggregated from China County-Level Data on Population and Agriculture, Keyed 1:1M GIS Map (CITAS and CIESIN, 1997). The grain output of each prefecture in 2015 was extracted from the yearbook of each province.

We adopted the mean centre analysis to describe the centrality of grain production and population distribution, expressed as equation [2]:

$$
\bar{s}=\left(\mu_{x}, \mu_{y}\right)=\left(\frac{\sum_{i=1}^{n} x_{i} W_{i}}{\sum_{i=1}^{n} W_{i}}, \frac{\sum_{i=1}^{n} y_{i} W_{i}}{\sum_{i=1}^{n} W_{i}}\right)
$$

where $\bar{s}$ represents the mean centre of grain production and population, the coordinates are denoted as $\mu_{x}$ and $\mu_{y} ; \mathrm{x}_{\mathrm{i}}$ and $\mathrm{y}_{\mathrm{i}}$ are the coordinates of the county $\mathrm{i}$, and weighting factor $\mathrm{W}_{\mathrm{i}}$ represents the grain production or population at the county i.

\section{Modelling the spatial flows of grain between prefectures in China}

Following Zuo et al. (2013, 2018), we adopted a doubly constrained spatial interaction model (SIM) to estimate the volume of grain transported between prefectures. This allocates the flows when both the grain output and consumption of each prefecture are known or estimated; hence the use of a doubly constrained SIM (Wilson, 1974). This can be expressed as the equations below:

$$
\begin{array}{r}
\widehat{m}_{i j}=A_{i} O_{i} B_{j} D_{j} f\left(d_{i j}\right), \quad(i, j=1,2,3 \ldots . r) \\
\sum_{j} \widehat{m}_{i j}=O_{i}, \quad(j=1,2,3 \ldots . r) \\
\sum_{i} \widehat{m}_{i j}=D_{j}, \quad(i=1,2,3 \ldots . r) \\
A_{i}=\frac{1}{\sum_{i} B_{j} D_{j} f\left(d_{i j}\right)}, \quad(i=1,2,3 \ldots . r) \\
B_{j}=\frac{1}{\sum_{j} A_{i} O_{i} f\left(d_{i j}\right)}, \quad(j=1,2,3 \ldots . r) \\
f\left(d_{i j}\right)=\exp \left(-\beta \cdot d_{i j}\right)
\end{array}
$$

where $\widehat{m}_{i j}$ represents the volume of grain transported from prefecture $\mathrm{i}$ to prefecture $\mathrm{j} ; O_{i}$ represents the output of grain at prefecture $\mathrm{i}$, and $D_{j}$ represents the consumption of grain at prefecture $\mathrm{j} . d_{i j}$ is the integrated transport cost of grain moved from prefecture $i$ to prefecture $j$, which can be generated by the transport model (explained in the following section). Both the equations [4] and [5] show how the SIM is doubly constrained at both the supply and demand sides. $A_{i}$ and $B_{j}$ are balancing factors to ensure the equation [4] and [5] hold. Since $A_{i}$ and $B_{j}$ are dependent on each other, Equation [6] and [7] are solved iteratively.

\section{Modelling the Transport Cost and Modal Choice}

We considered three different transport modes for grain transport, i.e. road, railway and waterway. 
For road transport, grain was assumed to be carried by High Gross Vehicles (HGVs) directly from the origins to the destinations. For grain transported by railway and waterway, the cost was measured by the distance equivalent between the origin and destination. We assumed that the grain was first transported by road from each origin to the closest railway station or wharf for loading. Then the loaded grain was carried by trains or ships to the railway station or wharf closest to the destination and unloaded for the final leg of the journey to the destination via the road network (illustrated in Extended Data Fig. $3)$. Relative cost converters were applied to convert the distance by railway or waterway to the road distance equivalent.

Thus $d_{i j}$ in equation [8] can be rewritten as in Equation [9], where superscripts RD, RL and WT indicate road, railway, and waterway, respectively. The 'shortest path' analysis was applied for road transport to estimate the transport cost between each pair of origin and destination. For railway and waterway transport, the 'closest facility' analysis was first applied to identify the closest railway station or wharf of each origin and destination; then the 'shortest path' analysis was applied to calculate the transport cost between the railway stations or between the wharves (equation [10] and [11]). In practice, the ArcGIS software was implemented to conduct these analyses.

$$
\begin{gathered}
d_{i j}=\min \left(d_{i j}^{R D}, d_{i j}^{R L}, d_{i j}^{W T}\right) \\
d_{i j}^{R L}=d_{i m}^{R D}+T C^{R L}+R C^{R L} * d_{m n}^{R L}+d_{n j}^{R D} \\
d_{i j}^{W T}=d_{i p}^{R D}+T C^{W T}+R C^{W T} * d_{p q}^{W T}+d_{n j}^{R D}
\end{gathered}
$$

Note that $R C^{R L}$ and $R C^{W T}$ are the two relative cost converters for railway and waterway, respectively. Considering the transport cost per ton-km for railway and waterway are lower than for road transport, these two relative cost converters need to be smaller than $1 . T C^{R L}$ and $T C^{W T}$ are the two transhipment costs for railway and waterway, respectively, which were introduced to quantify the cost of transferring grain between origins/destinations and railway stations/wharfs. These two values were calibrated against the observed average distance and market-share of railway or waterway transport in practice. The calibration process is described in the Supplementary Information.

\section{Estimating Carbon Emissions}

The carbon emission associated with the transport of grain was estimated based on the ton-km of grain transported by each transport mode multiplied by the corresponding carbon emission conversion factor (equation [12] and [13]).

$$
\begin{gathered}
C_{i j}^{T}=\widehat{m}_{i j} * d_{i j}^{R D} * C F^{R D}+\widehat{m}_{i j} * d_{i j}^{R L} * C F^{R L}+\widehat{m}_{i j} * d_{i j}^{W T} * C F^{W T} \\
\mathrm{C}^{T}=\sum_{i}^{n} \sum_{j}^{n} C_{i j}^{T}
\end{gathered}
$$

where $C_{i j}^{T}$ represents the carbon emission associated with the transport of grain from prefecture $\mathrm{i}$ to $\mathrm{j}$; and $\mathrm{C}^{T}$ represents the total carbon emission related to grain transport, $C F$ represents the carbon emission conversion factors, the superscripts RD, RL and WT denote the transport modes of road, railway, and waterway. Due to the lack of officially published carbon emission conversion factors in China, the $C F$ values were extracted from GHG Conversion Factors 2015, published by the Department of Environment and Food Affairs UK (Defra, 2016), and widely used in assessing $\mathrm{CO}_{2}$ and other greenhouse gas emissions by different industry sectors. Considering that the auto emission standards adopted in China (National Standards IV in 2015) are equivalent to the UK standards (Euro IV in 2015) 
since 2000, it is reasonable to use the UK GHG Conversion Factors to proximate the corresponding factors in China. Table 2 shows the conversion factors for each transport mode.

\section{Scenario Analysis}

The difference in carbon emissions associated with grain transport in China between 1990 and 2015 could be attributed to three factors, i.e. cropland displacement, change of dietary structure and development of transport infrastructure. In order to identify the impacts of these three factors on carbon emissions, we constructed a baseline scenario and two alternative scenarios.

- Baseline Scenario: all the three factors, i.e. cropland displacement, dietary changes, and transport infrastructure development, were modelled based on the observed data of 1990 and 2015;

- Alternative Scenario 1 ("unchanged transport network" scenario): the transport infrastructure remained as in 1990; while the other two factors change as Baseline Scenario;

- Alternative Scenario 2 ("unchanged dietary structure" scenario): the dietary structure for urban and rural residents in China remains as in 1990, while the other two factors change as the Baseline Scenario.

Assuming the carbon intensity of grain remains as in 1990, the transport-related carbon emission of grain should increase 1.04 million tons by 2015 , driven by population growth, which is much lower than 6.27 million tons as we estimated. To identify the different drivers of those increased carbon emissions, we further modelled the grain transport-related carbon emission under two alternative scenarios. According to the modelling results, the carbon emission associated with grain transportation was 11.27 million tons under Alternative Scenario 1 and 8.74 million tons under Alternative Scenario 2 (Figure 15).

The difference between the baseline scenario and the "unchanged transport network" scenario revealed the impact of transport infrastructure development on grain transport carbon emission, while the difference between the baseline scenario and the "unchanged dietary structure" scenario revealed the emission contribution of the dietary structure change. Then the rest part of the increment of grain transport carbon emission between 1990 and 2015 was attributed to cropland displacement.

\section{References}

China in Time and Space - CITAS - University of California-Davis, China in Time and Space CITAS - University of Washington, Center for International Earth Science Information Network CIESIN. 1997. China Dimensions Data Collection: China County-Level Data on Population (Census) and Agriculture, Keyed to 1:1M GIS Map. Palisades, NY: NASA Socioeconomic Data and Applications Center (SEDAC). https://doi.org/10.7927/H43N21B3. Accessed 1st 092020.

Clarke, M., \& Birkin, M. (2018). Spatial interaction models: From numerical experiments to commercial applications. Applied Spatial Analysis and Policy, 11(4), 713-729.

Dalin, C., Hanasaki, N., Qiu, H., Mauzerall, D. L., \& Rodriguez-Iturbe, I. (2014). Water resources transfers through Chinese interprovincial and foreign food trade. Proceedings of the National Academy of Sciences, 111(27), 9774-9779.

Leontief, W., \& Strout, A. (1963). Multiregional input-output analysis. In Structural interdependence and economic development (pp. 119-150). Palgrave Macmillan, London.

Reed, P., Minsker, B., \& Goldberg, D. E. (2000). Designing a competent simple genetic algorithm for search and optimization. Water Resources Research, 36(12), 3757-3761. 
Ricci, L. A. (1999). Economic geography and comparative advantage:: Agglomeration versus specialization. European Economic Review, 43(2), 357-377.

Samuelson, P. A. (1952). Spatial price equilibrium and linear programming. The American economic review, 42(3), 283-303.

Wilson, A. G. (1971). A family of spatial interaction models, and associated developments. Environment and Planning A, 3(1), 1-32.

Zuo, C., Birkin, M., Clarke, G., McEvoy, F., \& Bloodworth, A. (2013). Modelling the transport of primary aggregates in England and Wales: Exploring initiatives to reduce $\mathrm{CO} 2$ emissions. Land use policy, 34, 112-124.

Zuo, C., Birkin, M., Clarke, G., McEvoy, F., \& Bloodworth, A. (2018). Reducing carbon emissions related to the transport of aggregates: Is road or rail the solution?. Transport Research Part A: Policy and Practice, 117, 26-38. 


\section{Extended Data}

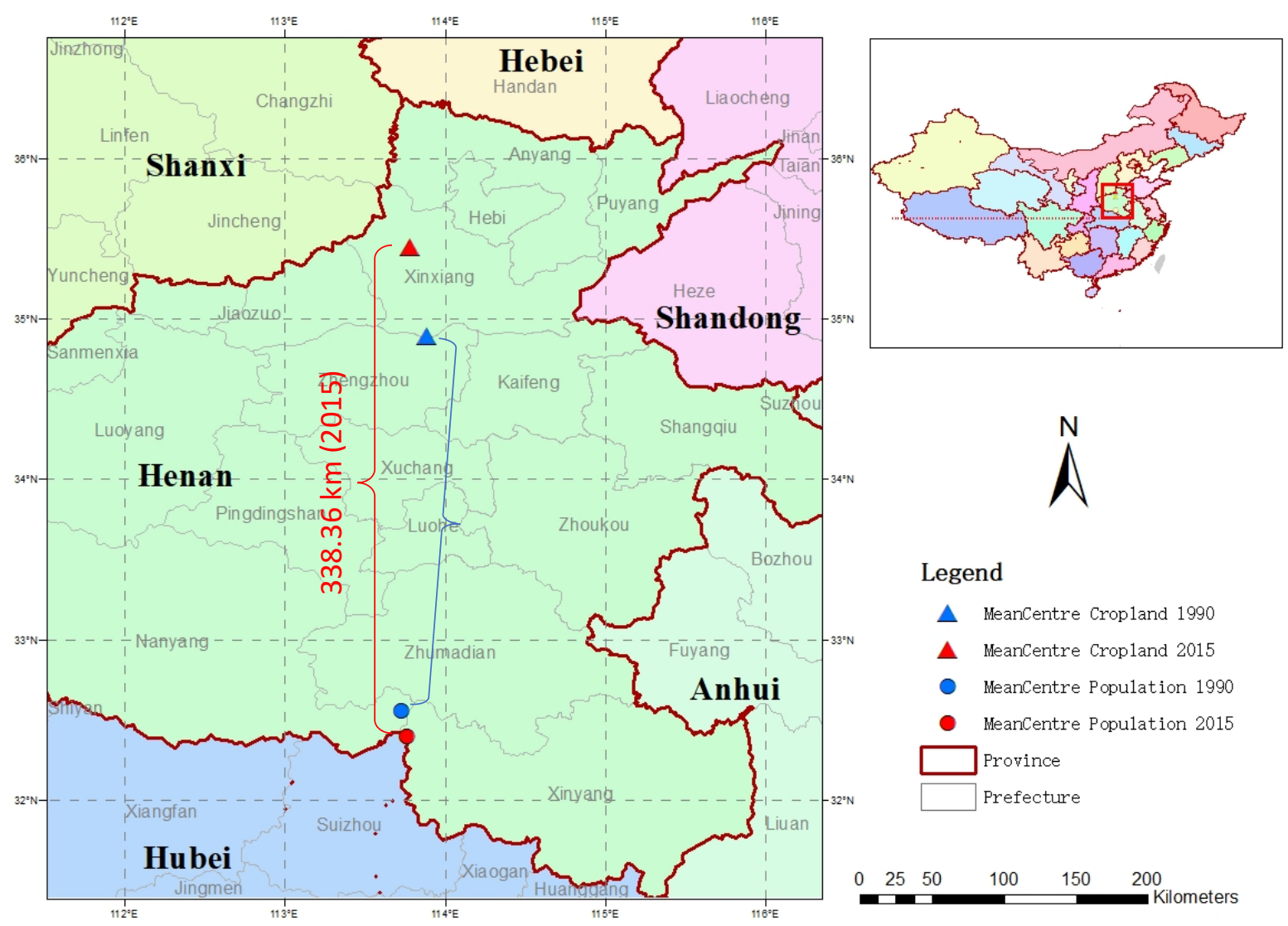

Extended Data Fig.1 Changes of Mean Centres of Cropland and Population at National Level, Chinese mainland, 1990-2015 


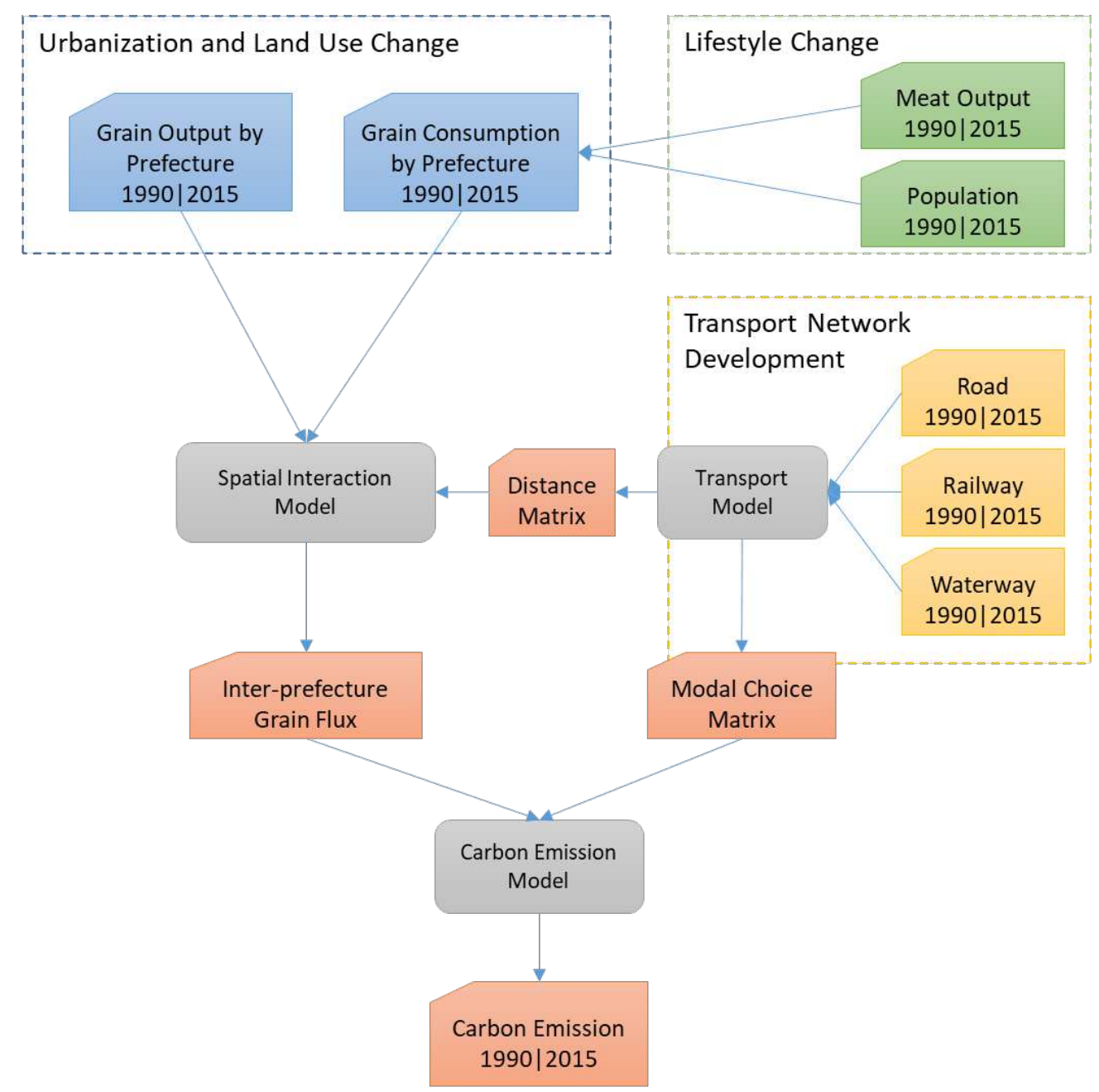

Extended Data Fig.2 Modelling Framework for Estimating Carbon Emission of Grain Transport

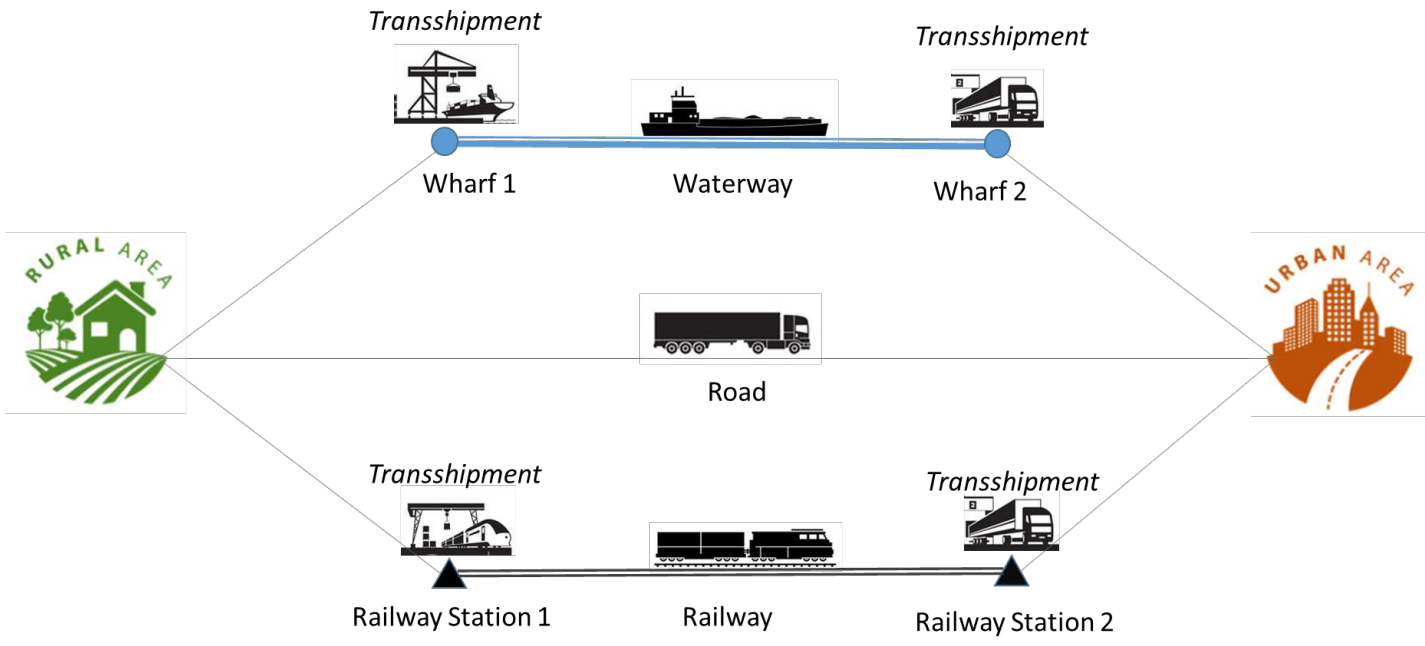

Extended Data Fig.3 Illustration of Transport Cost and Modal Choice Model 
Extended Data Table 1 Provincial average carbon footprints of grain transport for consumption and supply

\begin{tabular}{|c|c|c|}
\hline Province & $\begin{array}{l}\text { Carbon Intensity of Grain } \\
\text { Transport for Consumption } \\
\left(\mathrm{kgCO}^{2} \mathrm{e} / \mathrm{ton}\right)\end{array}$ & $\begin{array}{l}\text { Carbon Intensity of Grain } \\
\text { Transport for Supply } \\
\left(\mathrm{kgCO}^{2} \mathrm{e} / \mathrm{ton}\right)\end{array}$ \\
\hline Beijing & 38.45 & 13.75 \\
\hline Tianjin & 39.98 & 43.84 \\
\hline Hebei & 6.27 & 7.03 \\
\hline Shanxi & 10.28 & 9.31 \\
\hline $\begin{array}{l}\text { Neimenggu (Inner } \\
\text { Mongolia) }\end{array}$ & 6.69 & 41.98 \\
\hline Liaoning & 22.79 & 41.13 \\
\hline Jilin & 6.21 & 37.57 \\
\hline Heilongjiang & 5.21 & 42.87 \\
\hline Shanghai & 34.40 & 4.57 \\
\hline Jiangsu & 16.25 & 11.09 \\
\hline Zhejiang & 30.24 & 2.37 \\
\hline Anhui & 5.81 & 13.07 \\
\hline Fujian & 35.59 & 3.33 \\
\hline Jiangxi & 8.65 & 5.43 \\
\hline Shandong & 8.87 & 11.16 \\
\hline Henan & 2.54 & 11.32 \\
\hline Hubei & 8.24 & 7.07 \\
\hline Hunan & 5.92 & 1.47 \\
\hline Guangdong & 45.39 & 2.06 \\
\hline Guangxi & 31.89 & 3.44 \\
\hline Hainan & 44.77 & 4.14 \\
\hline Chongqing & 1.64 & 0.92 \\
\hline Sichuan & 14.02 & 3.32 \\
\hline Guizhou & 15.78 & 1.18 \\
\hline Yunnan & 34.26 & 5.48 \\
\hline Xizang (Tibet) & 77.18 & 24.80 \\
\hline Shaanxi & 14.44 & 3.94 \\
\hline Gansu & 11.05 & 13.22 \\
\hline Qinghai & 57.60 & 31.04 \\
\hline Ningxia & 6.90 & 19.98 \\
\hline Xinjiang & 8.51 & 31.67 \\
\hline
\end{tabular}

Extended Data Table 2 GHG Conversion Factors by Transport Mode

\begin{tabular}{ll}
\hline Transport Mode & $\begin{array}{l}\text { Carbon Emission Conversion Factor } \\
\left(\mathrm{kgCO}^{2} \mathrm{e} / \mathrm{ton}-\mathrm{km}\right)\end{array}$ \\
\hline Road (HGV) & 0.11364 \\
Railway & 0.02601 \\
Waterway & 0.01315
\end{tabular}




\section{Supplementary Files}

This is a list of supplementary files associated with this preprint. Click to download.

- SupplementaryInformation.docx 